\title{
Tissue factor contributes to neutrophil CD11b expression in alpha-naphthylisothiocyanate-treated mice
}

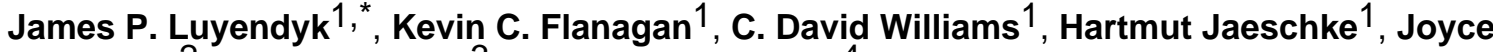 \\ G. Slusser ${ }^{2}$, Nigel Mackman ${ }^{3}$, and Glenn H. Cantor ${ }^{4}$ \\ ${ }^{1}$ Department of Pharmacology, Toxicology and Therapeutics, The University of Kansas Medical \\ Center, Kansas City, KS \\ ${ }^{2}$ Flow Cytometry Core Laboratory, The University of Kansas Medical Center, Kansas City, KS \\ ${ }^{3}$ Division of Hematology/Oncology, Department of Medicine, University of North Carolina, Chapel \\ Hill, NC \\ ${ }^{4}$ Discovery Toxicology, Bristol-Myers Squibb, Princeton, NJ
}

\begin{abstract}
Cholestatic liver injury induced by alpha-naphthylisothiocyanate (ANIT) is provoked by injury to intrahepatic bile ducts and the progression of hepatic necrosis requires the procoagulant protein tissue factor (TF) and extrahepatic cells including neutrophils. Recent studies have shown that myeloid cell TF contributes to neutrophil activation. We tested the hypothesis that myeloid cell TF contributes to neutrophil activation in ANIT-treated mice. TF activity in liver homogenates increased significantly in $\mathrm{TF}^{\text {flox/flox }}$ mice treated with ANIT, but not in $\mathrm{TF}^{\text {flox/flox/LysMCre mice }}$ ( $\mathrm{TF}^{\Delta \text { Myeloid }}$ mice), which have reduced TF expression in monocytes/macrophages and neutrophils. Myeloid cell-specific TF deficiency did not alter expression of the chemokines KC or MIP-2, but reduced hepatic neutrophil accumulation in ANIT-treated mice at 48 hours as indicated by tissue myeloperoxidase (MPO) activity. Myeloid cell TF deficiency significantly reduced CD11b expression by blood neutrophils in ANIT-treated mice and this was associated with reduced plasma MPO protein levels, an index of neutrophil degranulation. However, myeloid cell-specific TF deficiency had no effect on ANIT-induced coagulation cascade activation. The increase in serum ALT and ALP activities in ANIT-treated mice was reduced by myeloid cell TF deficiency $(\mathrm{p}<0.05)$, but the myeloid cell TF deficiency did not reduce hepatic necrosis at 48 hours, as determined by histopathology and morphometry. The results suggest that myeloid cell TF contributes to neutrophil CD11b expression during cholestasis by a coagulation-independent pathway. However, the resultant reduction in neutrophil accumulation/activation is insufficient to substantially reduce ANIT hepatotoxicity, suggesting that myeloid cell TF is only one of many factors modulating hepatic necrosis during cholestasis.
\end{abstract}

(C) 2010 Elsevier Inc. All rights reserved.

*To whom correspondence should be addressed James P. Luyendyk, Ph.D. Department of Pharmacology, Toxicology and Therapeutics The University of Kansas Medical Center 3901 Rainbow Blvd, MS-1018 Kansas City, KS 66160 Phone: (913) 588-9974 Fax: (913) 588-7501 jluyendyk@kumc.edu.

Publisher's Disclaimer: This is a PDF file of an unedited manuscript that has been accepted for publication. As a service to our customers we are providing this early version of the manuscript. The manuscript will undergo copyediting, typesetting, and review of the resulting proof before it is published in its final citable form. Please note that during the production process errors may be discovered which could affect the content, and all legal disclaimers that apply to the journal pertain.

Conflict of Interest: The authors declare no significant conflict of interest for the work described herein. 


\section{Keywords}

Hepatotoxicity; coagulation; neutrophils; tissue factor; cholestasis

\section{Introduction}

The xenobiotic alpha-naphthylisothiocyanate (ANIT) induces acute cholestatic liver injury in rodents (Plaa et al., 1976). ANIT-induced bile duct epithelial cell (BDEC) injury releases high concentrations of bile acids into the hepatic parenchyma. Several studies have indicated that the progression of hepatic necrosis during acute cholestasis requires inflammatory mediators. In the case of ANIT-induced liver damage, neutrophils have also been shown to contribute to hepatocyte injury (Dahm et al., 1991;Kodali et al., 2006). Moreover, we have shown that tissue factor (TF), a primary activator of blood coagulation, contributes to ANITinduced liver damage (Luyendyk et al., 2009). However, the interplay between tissue factor and neutrophils in cholestatic liver injury has not been explored in detail.

$\mathrm{TF}$ is the transmembrane receptor for coagulation factor VIIa and has various roles in physiology and disease (Mackman, 2004). ANIT-induced hepatocellular necrosis was reduced in low TF mice (Luyendyk et al., 2009), which express TF at $1 \%$ of normal levels in all cells (Parry et al., 1998). Moreover, ANIT-induced generation of the coagulation protease thrombin and deposition of fibrin in the liver were TF-dependent (Luyendyk et al., 2009). However, the mechanism whereby TF contributes to the progression of acute cholestatic liver injury in this model is not known.

The mechanisms underlying neutrophil-dependent progression of various liver injury processes including cholestasis have been extensively studied (Jaeschke, 2006). A key feature of all inflammatory injury models is the activation of circulating neutrophils as indicated by the increased expression of Mac-1, a heterodimeric integrin comprising CD11b and CD18, which is needed for extravasation and attack on target cells (Jaeschke, 2006). The expression of Mac-1 increases in neutrophils after ligation of the common bile duct (BDL) in mice, and CD18 deficiency reduced necrosis in this model (Gujral et al., 2003). Similarly, CD18 deficiency reduced necrosis in ANIT-treated mice (Kodali et al., 2006). Interaction of Mac-1 with ICAM-1 participates in hepatic neutrophil recruitment and stimulates terminal neutrophil activation and the release of cytotoxic mediators including reactive oxygen and proteases that damage hepatocytes (Gujral et al., 2004). Of importance, the mechanisms of CD11b expression by neutrophils during ANIT-induced cholestasis have not been investigated.

TF has been shown to contribute to neutrophil activation. Neutrophils have been shown recently to express $\mathrm{TF}$ in a form that participates in the oxidative burst, but not in activation of the coagulation cascade (Redecha et al., 2008). The mechanism whereby TF promoted neutrophil activation required protease activated receptor-2 (PAR-2), also expressed by neutrophils (Redecha et al., 2008). Interestingly, another study showed that stimulation of PAR-2 also increased the expression of CD11b by isolated neutrophils (Howells et al., 1997). These studies suggest a potential pathway whereby TF could promote the expression of CD11b by neutrophils. However, this has not been investigated in a model of neutrophildependent hepatotoxicity.

In the present study, we used a genetic approach to determine the role of TF expressed by myeloid cells in ANIT-induced neutrophil activation, coagulation and hepatic injury. 


\section{Materials and Methods \\ Mice}

Male mice between the ages of 8-16 weeks were used for these studies. Generation of the $\mathrm{TF}^{\text {flox/flox }}$ mice has been described previously (Pawlinski et al., 2007). Crossing the $\mathrm{TF}^{\text {flox/flox }}$ mice with mice expressing the Cre recombinase under control of the M Lysozyme (LysM) promoter selectively reduces TF expression in myeloid cells (neutrophils and macrophages) by $>90 \%$ (Redecha et al., 2007; Pawlinski et al., 2010). Littermate $\mathrm{TF}^{\text {flox/flox/ }}$ LysMCre mice (hereafter referred to as $\mathrm{TF}^{\Delta \text { Myeloid }}$ mice) and $\mathrm{TF}^{\text {flox/flox }}$ mice (hereafter referred to as control mice) on an identical genetic background (N6 C57Bl/6J) were used for experiments. These mice were generated by breeding male $\mathrm{TF}^{\Delta \text { Myeloid }}$ mice with female control mice. Mice were maintained in an AAALAC-accredited facility at the University of Kansas Medical Center. Mice were housed at an ambient temperature of $22^{\circ} \mathrm{C}$ with alternating 12-h light/dark cycles, and allowed water and rodent chow ad libitum (Teklad 8604; Harlan, Indianapolis, IN). All animal procedures were performed according to the guidelines of the American Association for Laboratory Animal Science and were approved by the KUMC Institutional Animal Care and Use Committee.

\section{ANIT hepatotoxicity model}

Mice fasted overnight were treated with a single dose of alpha-naphthylisothiocyanate (ANIT) (Sigma-Aldrich, St. Louis, MO) dissolved in corn oil $(60 \mathrm{mg} / \mathrm{kg}$, p.o.) or corn oil alone (control [vehicle] treatment) at $10 \mathrm{ml} / \mathrm{kg}$. Food was removed at $6 \mathrm{pm}$ and returned after treatment with ANIT or vehicle between 8-9 am. The mice were anesthetized using isoflurane 24 or 48 hours after ANIT treatment for the collection of blood and liver samples. Blood was collected from the caudal vena cava into a syringe containing sodium citrate (final concentration, $0.38 \%$ ) and additional blood was collected into a syringe without anticoagulant. Plasma and serum were collected from this blood by centrifugation. Sections of liver from the left lateral lobe were fixed in $10 \%$ neutral-buffered formalin. The right medial lobe was cut into a cube and affixed to a cork using OCT and frozen for 3 minutes in liquid nitrogen-chilled isopentane. The remaining liver was snap frozen in liquid nitrogen.

\section{Tissue myeloperoxidase (MPO) activity and plasma MPO levels}

Neutrophil accumulation in the liver was estimated by measuring liver homogenate MPO activity. $100 \mathrm{mg}$ of frozen liver was homogenized in a buffer containing $0.5 \%$ hexadecyl trimethyl ammonium bromide, $10 \mathrm{mM}$ EDTA and $50 \mathrm{mM} \mathrm{Na}_{2} \mathrm{PO}_{4}, \mathrm{pH} 5.4$ and subjected to 3 freeze-thaw cycles followed by centrifugation at $12,000 \times \mathrm{g}$ for 15 minutes at $4^{\circ} \mathrm{C}$. MPO activity in the supernatant was determined by addition of $50 \mathrm{mM} \mathrm{Na} 2 \mathrm{PO}_{4}$ containing 0.167 $\mathrm{mg} / \mathrm{ml}$ o-dianisidine dihydrochloride (Sigma) and $0.0005 \%$ hydrogen peroxide (Sigma) in $50 \mathrm{mM}$ phosphate buffer ( $\mathrm{pH}$ 6.0). MPO activity was expressed as the change in absorbance measured at $460 \mathrm{~nm}$ per $\mathrm{mg}$ of protein in the liver homogenate. Plasma MPO protein levels were determined using a commercial ELISA (Cell Sciences, Canton, MA).

\section{Clinical chemistry and chemokine measurement}

The serum activities of alanine aminotransferase (ALT) and alkaline phosphatase (ALP) were determined using commercially available reagents (Thermo Scientific). Levels of KC and MIP-2 protein in the plasma were determined using commercial ELISAs (R\&D Systems, Minneapolis, MN).

\section{Evaluation of liver tissue factor activity, thrombin generation, and liver fibrin deposition}

Coagulation cascade activation terminates in generation of the protease thrombin. Antithrombin in the plasma binds rapidly to thrombin, inhibiting its activity. The thrombinantithrombin complex (TAT) is relatively stable in plasma and is extensively utilized as an 
indicator of thrombin generation/coagulation cascade activation. TAT levels in plasma were determined using a commercial ELISA kit (Siemens Healthcare Diagnostics, Deerfield, IL). Procoagulant (TF) activity of liver homogenates was performed as described previously (Ganey et al., 2007) using a single-stage clotting assay. In brief, $100 \mathrm{mg}$ of snap-frozen liver was homogenized in HEPES/saline containing $15 \mathrm{mM} \mathrm{N}$-octyl-D-glucopyranoside. $50 \mu \mathrm{L}$ of this homogenate was added to an equal amount of citrated mouse plasma (Equitech Bio, Carroll, TX) and $25 \mathrm{mM} \mathrm{CaCl} 2$ added to activate the coagulation cascade. The time to clot formation was evaluated using a STart4 coagulation analyzer (Diagnostica Stago) and compared to a standard curve generated using mouse-brain extract (a source of mouse tissue factor). The TF-dependent procoagulant activity of each sample was identified by repeating each assay in the presence of an inhibitory rat anti-mouse TF antibody $(100 \mu \mathrm{g} / \mathrm{ml}, 1 \mathrm{H} 1)$, kindly provided by Dr. Daniel Kirchhofer (Genentech). Hepatic fibrin in liver extracts was detected by Western blotting using the mouse anti-human fibrin antibody (59D8, kindly provided by Dr. Charles Esmon, Oklahoma Medical Research Foundation) as described previously (Luyendyk et al., 2009). This antibody detects fibrin at an epitope revealed specifically by thrombin cleavage of fibrinogen (Weiler-Guettler et al., 1998).

\section{RNA isolation, cDNA synthesis, and real-time PCR}

RNA was isolated from approximately $100 \mathrm{mg}$ of snap-frozen liver using TRI reagent (Molecular Research Center, Inc., Cincinnati, OH). cDNA synthesis was performed using 1 microgram of RNA and a High Capacity cDNA Reverse Transcription kit (Applied Biosystems) and MyCycler thermal cycler (Bio-Rad). Levels of ICAM-1 and GAPDH mRNA were determined using TaqMan gene expression assays and TaqMan gene expression master mix (Applied Biosystems) on an ABI Prism 7300 sequence detection system (Applied Biosystems). The expression of ICAM-1 mRNA was normalized relative to GAPDH expression levels, and relative expression level determined using the comparative Ct method.

\section{Cytokeratin-19 staining and quantification}

5 micron frozen sections obtained from livers frozen in isopentane/OCT were used. For cytokeratin 19 (CK19) staining, sections were fixed in 4\% neutral-buffered formalin and then blocked with $10 \%$ goat serum in PBS for 1 hour at room temperature. The sections were then washed with PBS and incubated with the monoclonal rat anti-mouse CK19 antibody (1:1000 in block buffer, clone, TROMA-3). The TROMA-3 antibody developed by R. Kemler (Brulet et al., 1980) was obtained from the Developmental Studies Hybridoma Bank developed under the auspices of the NICHD and maintained by The University of Iowa, Department of Biology, Iowa City, IA. The sections were incubated with anti-rat Alexa-conjugated secondary antibody (Invitrogen), washed with PBS, counterstained with DAPI, and coverslipped. The area of positive CK-19 staining was determined in 5 randomly selected 100X magnification images utilizing Scion Image Software.

\section{Histopathology}

Formalin-fixed livers (48 hours post-dosing) were subjected to routine processing, sectioned at 5 microns, stained with hematoxylin and eosin, and evaluated by light microscopy. At least two sections of liver were evaluated from each animal. Sections were approximately 1 to $1.5 \mathrm{~cm}$ long and 0.3 to $0.5 \mathrm{~cm}$ wide (at the widest part). Each section was evaluated in its entirety. The severity of necrosis was also assigned a score by a pathologist (G.H.C) in a masked fashion, using a scale of 0 to 5, as we have described previously (Luyendyk et al., 2009). In addition, morphometry was performed. The slides were scanned using a ScanscopeXT (Aperio, Vista CA), foci of necrosis (i.e., bile infarcts) were identified and circled manually, and the area of necrosis determined by Spectrum Imagescope software 
(Aperio, Vista CA). The percent of necrosis was determined by dividing the sum of the necrotic areas by the total area of the sections.

\section{Flow cytometry}

Neutrophil CD11b expression by cells expressing high levels of Gr-1, a marker of mature granulocytes (Hestdal et al., 1991;Fleming et al., 1993) was assessed as described previously (Williams et al., 2010). Briefly, whole blood containing heparin as anticoagulant was collected and immediately placed on ice. $0.5 \mu \mathrm{g}$ of Cy5-labeled-anti-Gr-1 (BioLegend, San Diego, CA) and PE-labeled-anti-CD11b (BioLegend) diluted in 0.1\% BSA/PBS were added to $50 \mu \mathrm{L}$ whole blood. Tubes were incubated for 30 minutes on ice in the dark. After washing with $0.1 \%$ BSA, red blood cells were lysed using RBC lysing solution $(0.155 \mathrm{M}$ $\mathrm{NH} 4 \mathrm{Cl}, 10 \mathrm{mM}$ KHCO3, $0.1 \mathrm{mM}$ EDTA). Pelleted cells were washed three times with $0.1 \%$ BSA then fixed with $2.5 \%$ buffered formalin. Samples were analyzed on the FACSCalibur (BD, Franklin Lakes, NJ).

\section{Statistics}

Comparison of two groups was performed using Student's $t$-test. Comparison of 3 or more groups was performed using one-way analysis of variance and Student-Newman-Keul's post-hoc test. Datasets resistant to transformation to achieve a normal distribution were compared utilizing the Mann-Whitney Rank Sum Test. The criterion for statistical significance was $\mathrm{P} \leq 0.05$.

\section{Results}

\section{Effect of myeloid cell-specific TF deficiency on liver procoagulant activity and coagulation} cascade activation in ANIT-treated mice

In agreement with our previous studies (Luyendyk et al., 2009), liver procoagulant (TF) activity increased 48 hours after ANIT treatment in control mice (TF flox/flox mice) (Fig. 1A). This increase was reduced by approximately $50 \%$ in $\mathrm{TF}^{\Delta \text { Myeloid }}$ mice treated with ANIT (Fig. 1A). This result is consistent with the hypothesis that myeloid cells expressing TF accumulate in livers of ANIT-treated mice. Unlike our previous finding that ANIT-induced thrombin generation is reduced by $>75 \%$ in low TF mice (Luyendyk et al., 2009), plasma thrombin-antithrombin (TAT) levels were not significantly affected by myeloid cell TF deficiency in ANIT-treated mice at 24 or 48 hours (Fig. 1B). Similarly, hepatic fibrin deposition in livers at 48 hours was not significantly affected by myeloid cell TF deficiency (Fig. 1C).

\section{Effect of myeloid cell-specific TF deficiency on neutrophil CD11b expression in ANIT- treated mice}

Mature neutrophils in the blood express high levels of Gr-1 (Hestdal et al., 1991;Fleming et al., 1993) and during cholestasis these cells are stimulated to express increased levels of CD11b (Gujral et al., 2003). CD11b expression on circulating neutrophils reflects CD11b expression on liver accumulated neutrophils (Williams et al., 2010). To determine whether myeloid cell TF contributed to Gr-1 or CD11b expression on circulating neutrophils, we utilized flow cytometry. ANIT treatment increased the percentage of Gr-1-high cells (i.e., mature granulocytes) in the blood, and this was significantly reduced in $\mathrm{TF}^{\Delta \mathrm{Myeloid}}$ mice (Fig. 2A). Neutrophil CD11b expression and the percentage of Gr-1-high/CD11b-high cells increased in ANIT-treated mice, and this was significantly reduced by myeloid cell TF deficiency (Fig. 2B-C). These results suggest that myeloid cell TF deficiency impairs neutrophil CD11b priming in ANIT-treated mice. In agreement with this result, plasma MPO levels, an index of neutrophil degranulation (Stegenga et al., 2008;Su et al., 2005;van 
Leeuwen et al., 2008), were reduced in ANIT-treated $\mathrm{TF}^{\Delta \text { Myeloid }}$ mice compared to ANITtreated control mice (Fig. 2D).

\section{Effect of myeloid cell-specific TF deficiency on liver myeloperoxidase activity, chemokine and ICAM-1 expression in ANIT-treated mice}

The accumulation of neutrophils in the liver was determined by measuring the activity of myeloperoxidase (MPO) in tissue homogenates. Tissue MPO activity increased to a similar extent in both ANIT-treated control mice and ANIT-treated $\mathrm{TF}^{\Delta \text { Myeloid }}$ mice at 24 hours (Fig. 3A). In contrast, tissue MPO activity was significantly decreased in ANIT-treated $\mathrm{TF}^{\Delta \text { Myeloid }}$ mice at 48 hours (Fig. 3A). Myeloid cell TF deficiency did not impact the increase in plasma levels of the neutrophil chemokines KC and MIP-2 (Fig. 3B-C) or induction of ICAM-1 mRNA in liver (Fig. 3D). The data indicate that reducing myeloid cell TF expression reduces hepatic neutrophil accumulation without impacting ICAM-1 or chemokine expression.

\section{Effect of myeloid cell-specific TF deficiency on ANIT-induced liver injury}

Early ANIT-induced biliary injury is elicited by an ANIT-GSH conjugate transported into the bile by canalicular MRP2 in hepatocytes (Dietrich et al., 2001;Carpenter-Deyo et al., 1991). Of importance, myeloid cell TF deficiency did not affect basal MRP2 mRNA expression in liver (data not shown). Serum ALT and ALP activities increased in ANITtreated control mice at 24 hours and increased further at 48 hours. The increase in these biomarkers of injury was attenuated in ANIT-treated $\mathrm{TF}^{\Delta \text { Myeloid }}$ mice (Fig. 4A-B). Despite this reduction in ALT, there was no reduction in necrosis in ANIT-treated $\mathrm{TF}^{\Delta \text { Myeloid }}$ mice (Fig. 4C), as determined by histopathologic examination and assignment of a necrosis severity score as we have described previously (Luyendyk et al., 2009). This conclusion is supported by morphometric examination, which did not identify a statistically significant difference in the area of necrosis between groups at 48 hours (Fig. 4D). Biliary hyperplasia, as indicated by an increase in cytokeratin-19 (CK-19) staining, was not affected by myeloid cell TF deficiency (Fig. 4E, Supplemental Fig. 1).

\section{Discussion}

It is increasingly clear that TF can contribute to disease by mechanisms independent of coagulation cascade activation (Versteeg et al., 2006). An important example of this contribution is a series of experiments indicating that TF expressed by neutrophils contributes to the oxidative burst within these cells (Redecha et al., 2007). In light of our previous studies showing that TF deficiency in all cells reduces ANIT-induced liver injury, we tested the hypothesis that myeloid cell TF contributed to neutrophil activation and hepatotoxicity in ANIT-treated mice. Overall, the results suggest that TF contributes to CD11b upregulation by neutrophils in ANIT-treated mice, but that this effect is insufficient to significantly affect ANIT-induced liver necrosis 48 hours after ANIT administration. However, we cannot exclude the possibility that myeloid cell TF-deficiency impacts ANITinduced liver injury at later time points (e.g., 72 hours) during the early phase of liver repair (Ohta et al., 1999).

TF can exist in a form that participates in cell signaling, but does not activate blood coagulation (Ahamed et al., 2006). For example, in a model of anti-phospholipid antibodyinduced pregnancy loss, the amplication of neutrophil activation by TF was not inhibited by the monoclonal antibody 5G9, which selectively inhibits procoagulant TF (Redecha et al., 2008). Interestingly, liver procoagulant activity was reduced in ANIT-treated $\mathrm{TF}^{\Delta \text { Myeloid }}$ mice, suggesting a contribution of myeloid cells to hepatic TF antigen levels during cholestatic liver injury. However, myeloid cell TF deficiency did not affect coagulation 
cascade activation in ANIT-treated mice. This discrepancy may be due to the assay utilized to measure liver TF activity. We utilized an assay of liver TF procoagulant involving the detergent, $N$-octyl-glucopyranoside, which converts cryptic non-procoagulant TF to a procoagulant form detected by the assay (Versteeg et al., 2007). Accordingly, the level of TF activity in liver homogenate does not necessarily reflect the ability of myeloid cell TF to elicit coagulation cascade activation in vivo.

In contrast to myeloid cell-specific TF deficiency, global TF-deficiency reduced coagulation and liver necrosis in ANIT-treated mice. This indicates that TF expression by another cell type is essential for thrombin generation, and that thrombin likely participates in ANIT hepatotoxicity. Indeed, we found that both hepatic fibrin and the thrombin receptor PAR-4 contribute to ANIT-induced liver injury in mice (Luyendyk et al., 2010). Candidate cell types expressing TF required for thrombin generation in this model include BDECs and hepatocytes, both of which are damaged during the progression of ANIT-induced liver injury, and have been shown to express TF (Stephenne et al., 2007;Luyendyk et al., 2009). TF staining colocalized with the BDEC marker cytokeratin-19 in the livers of ANIT-treated mice suggests exposure of BDEC-derived TF to the sinusoidal blood near areas of necrosis (Luyendyk et al., 2009). However, additional studies are required to determine the cell type expressing TF required for ANIT-induced coagulation.

Neutrophils are key players in the progression of cell injury in various models of liver disease, including cholestatic liver injury (Gujral et al., 2003;Kodali et al., 2006). Sequential activation of neutrophils during cholestasis involves upregulation of adhesion molecules including Mac-1 (CD11b/CD18) on circulating neutrophils, accumulation in the liver, which likely involves to some extent the chemokines MIP-2 and KC (Xu et al., 2004), and transmigration across the sinusoidal endothelium. The engagement of Mac-1 with ICAM-1 expressed by hepatocytes triggers terminal activation resulting in neutrophil degranulation and formation of a long-lasting oxidant stress in close proximity to hepatocytes (Gujral $e t$ al., 2003;Gujral et al., 2004). Interestingly, we found that myeloid cell TF deficiency significantly reduced neutrophil priming in the blood, evidenced by reduced cell surface expression of CD11b. Indeed, systemic activation of neutrophils, as indicated by increased CD11b expression, is observed in other models where neutrophils contribute to liver injury, including hepatic ischemia-reperfusion (Jaeschke et al., 1993) and obstructive cholestasis (Gujral et al., 2003). In ANIT-treated mice, the increased CD11b expression occurred with the increase in plasma MPO activity, which is a marker of neutrophil degranulation (Stegenga et al., 2008;Su et al., 2005; van Leeuwen et al., 2008). The fact that TF deficiency reduced CD11b expression and plasma MPO levels suggests that TF contributes to the upregulation of adhesion molecules on neutrophils and promotes neutrophil cytotoxicity during cholestasis. In another model, a similar activation of neutrophils by TF was identified, and determined to involve the TF cytoplasmic domain and PAR-2 (Redecha et al., 2008). Indeed, stimulation of PAR-2 on neutrophils increases surface expression of CD11b (Howells et al., 1997). Taken together, the results support the hypothesis that TF contributes to neutrophil activation during cholestasis.

ANIT-induced liver necrosis was reduced in low TF mice, which have TF levels reduced to near $1 \%$ of normal in all cells (Luyendyk et al., 2009). Although the reduction in CD11b expression by neutrophils in ANIT-treated $\mathrm{TF}^{\Delta \text { Myeloid }}$ mice was associated with a significant reduction in serum ALT and ALP activities, our study did not identify a significant effect on necrosis in ANIT-treated $\mathrm{TF}^{\Delta \text { Myeloid }}$ mice. The lack of effect on myeloid cell TF deficiency on necrosis could also relate to the incomplete inhibition of neutrophil activation in these mice. Indeed, the presence of a threshold for neutrophil-dependent hepatotoxicity is evident in several models of liver injury, including ANIT-induced cholestasis. For example, in liver ischemia-reperfusion, reducing the number of circulating neutrophils by $65 \%$ did not affect 
liver injury, whereas a reduction of approximately $90 \%$ significantly reduced necrosis (Jaeschke et al., 1990). In a model of endotoxin/D-galactosamine-induced liver injury, extravasation of approximately $30 \%$ of accumulated neutrophils is sufficient to produce maximal hepatotoxicity (Essani et al., 1995). With respect to the ANIT model, hepatic neutrophil accumulation is reduced by $50 \%$ in CXCR2 $2^{-/-}$mice, but hepatocellular injury is unaffected (Xu et al., 2004). Similarly, whereas a complete loss of CD18 reduced ANITinduced necrosis in mice, a $70 \%$ reduction in CD18 levels was insufficient to affect the progression of ANIT-induced liver injury in mice (Kodali et al., 2006). Myeloid cell TF deficiency did not completely prevent $\mathrm{CD} 11 \mathrm{~b}$ upregulation on circulating neutrophils, nor did it abolish the increase in plasma MPO, suggesting that substantial neutrophil activation

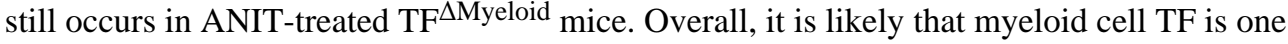
of many factors contributing to neutrophil activation and hepatotoxicity in this model.

\section{Supplementary Material}

Refer to Web version on PubMed Central for supplementary material.

\section{Acknowledgments}

The authors would like to thank Huina Cai and Ruipeng (Frank) Wang for outstanding technical assistance, Linda Watson (Bristol-Myers Squibb) for assistance with the morphometric analysis, and Bradley Sullivan for critical reading of the manuscript. Supported by the National Institutes of Health R01 ES017537 (JPL) and COBRE (Center of Biomedical Research Excellence) P20 RR021940. DW was supported in part by a training grant from the National Institutes of Health (T32ES007079).

\section{Reference List}

1. Ahamed J, Versteeg HH, Kerver M, Chen VM, Mueller BM, Hogg PJ, Ruf W. Disulfide isomerization switches tissue factor from coagulation to cell signaling. Proc.Natl.Acad Sci U.S.A 2006;103:13932-13937. [PubMed: 16959886]

2. Brulet P, Babinet C, Kemler R, Jacob F. Monoclonal antibodies against trophectoderm-specific markers during mouse blastocyst formation. Proc.Natl.Acad.Sci.U.S.A 1980;77:4113-4117. [PubMed: 6933460]

3. Carpenter-Deyo L, Marchand DH, Jean PA, Roth RA, Reed DJ. Involvement of glutathione in 1naphthylisothiocyanate (ANIT) metabolism and toxicity to isolated hepatocytes. Biochem.Pharmacol 1991;42:2171-2180. [PubMed: 1958235]

4. Dahm LJ, Schultze AE, Roth RA. An antibody to neutrophils attenuates alphanaphthylisothiocyanate-induced liver injury. J.Pharmacol.Exp.Ther 1991;256:412-420. [PubMed: 1846424]

5. Dietrich CG, Ottenhoff R, de Waart DR, Oude Elferink RP. Role of MRP2 and GSH in intrahepatic cycling of toxins. Toxicology 2001;167:73-81. [PubMed: 11557131]

6. Essani NA, Fisher MA, Farhood A, Manning AM, Smith CW, Jaeschke H. Cytokine-induced upregulation of hepatic intercellular adhesion molecule-1 messenger RNA expression and its role in the pathophysiology of murine endotoxin shock and acute liver failure. Hepatology 1995;21:16321639. [PubMed: 7768509]

7. Fleming TJ, Fleming ML, Malek TR. Selective expression of Ly-6G on myeloid lineage cells in mouse bone marrow. RB6-8C5 mAb to granulocyte-differentiation antigen (Gr-1) detects members of the Ly-6 family. J.Immunol 1993;151:2399-2408. [PubMed: 8360469]

8. Ganey PE, Luyendyk JP, Newport SW, Eagle TM, Maddox JF, Mackman N, Roth RA. Role of the coagulation system in acetaminophen-induced hepatotoxicity in mice. Hepatology 2007;46:11771186. [PubMed: 17654741]

9. Gujral JS, Farhood A, Bajt ML, Jaeschke H. Neutrophils aggravate acute liver injury during obstructive cholestasis in bile duct-ligated mice. Hepatology 2003;38:355-363. [PubMed: 12883479] 
10. Gujral JS, Liu J, Farhood A, Hinson JA, Jaeschke H. Functional importance of ICAM-1 in the mechanism of neutrophil-induced liver injury in bile duct-ligated mice. Am.J.Physiol Gastrointest.Liver Physiol 2004;286:G499-G507. [PubMed: 14563671]

11. Hestdal K, Ruscetti FW, Ihle JN, Jacobsen SE, Dubois CM, Kopp WC, Longo DL, Keller JR. Characterization and regulation of RB6-8C5 antigen expression on murine bone marrow cells. J.Immunol 1991;147:22-28. [PubMed: 1711076]

12. Howells GL, Macey MG, Chinni C, Hou L, Fox MT, Harriott P, Stone SR. Proteinase-activated receptor-2: expression by human neutrophils. Journal of Cell Science 1997;110:881-887. [PubMed: 9133675]

13. Jaeschke H. Mechanisms of Liver Injury. II. Mechanisms of neutrophil-induced liver cell injury during hepatic ischemia-reperfusion and other acute inflammatory conditions. Am.J.Physiol Gastrointest.Liver Physiol 2006;290:G1083-G1088. [PubMed: 16687579]

14. Jaeschke H, Farhood A, Bautista AP, Spolarics Z, Spitzer JJ, Smith CW. Functional inactivation of neutrophils with a Mac-1 (CD11b/CD18) monoclonal antibody protects against ischemiareperfusion injury in rat liver. Hepatology 1993;17:915-923. [PubMed: 8387952]

15. Jaeschke H, Farhood A, Smith CW. Neutrophils contribute to ischemia/reperfusion injury in rat liver in vivo. The FASEB Journal 1990;4:3355-3359. [PubMed: 2253850]

16. Kodali P, Wu P, Lahiji PA, Brown EJ, Maher JJ. ANIT toxicity toward mouse hepatocytes in vivo is mediated primarily by neutrophils via CD18. Am.J.Physiol Gastrointest.Liver Physiol 2006;291:G355-G363. [PubMed: 16614373]

17. Luyendyk JP, Mackman N, Sullivan BP. Role of fibrinogen and protease activated receptors in acute xenobiotic-induced cholestatic liver injury. Toxicol.Sci. 2010 in press.

18. Luyendyk JP, Cantor GH, Kirchhofer D, Mackman N, Copple BL, Wang R. Tissue factordependent coagulation contributes to alpha-naphthylisothiocyanate-induced cholestatic liver injury in mice. Am.J.Physiol Gastrointest.Liver Physiol 2009;296:G840-G849. [PubMed: 19179621]

19. Mackman N. Role of tissue factor in hemostasis, thrombosis, and vascular development. Arteriosclerosis, Thrombosis, and Vascular Biology 2004;24:1015-1022.

20. Ohta Y, Kongo M, Sasaki E, Harada N. Change in hepatic antioxidant defense system with liver injury development in rats with a single alpha-naphthylisothiocyanate intoxication. Toxicology 1999;139:265-275. [PubMed: 10647926]

21. Parry GCN, Erlich JH, Carmeliet P, Luther T, Mackman N. Low levels of tissue factor are compatible with development and hemostasis in mice. Journal of Clinical Investigation 1998;101:560-569. [PubMed: 9449688]

22. Pawlinski R, Tencati M, Holscher T, Pedersen B, Voet T, Tilley RE, Marynen P, Mackman N. Role of cardiac myocyte tissue factor in heart hemostasis. J.Thromb.Haemost 2007;5:1693-1700. [PubMed: 17663739]

23. Pawlinski R, Wang JG, Owens AP III, Williams J, Antoniak S, Tencati M, Luther T, Rowley JW, Low EN, Weyrich AS, Mackman N. Hematopoietic and non-hematopoietic cell tissue factor activates the coagulation cascade in endotoxemic mice. Blood 2010;116:806-14. [PubMed: 20410508]

24. Plaa GL, Priestly BG. Intrahepatic cholestasis induced by drugs and chemicals. Pharmacol.Rev 1976;28:207-273. [PubMed: 16281]

25. Redecha P, Franzke CW, Ruf W, Mackman N, Girardi G. Neutrophil activation by the tissue factor/Factor VIIa/PAR2 axis mediates fetal death in a mouse model of antiphospholipid syndrome. Journal of Clinical Investigation 2008;118:3453-3461. [PubMed: 18802482]

26. Redecha P, Tilley R, Tencati M, Salmon JE, Kirchhofer D, Mackman N, Girardi G. Tissue factor: a link between $\mathrm{C} 5 \mathrm{a}$ and neutrophil activation in antiphospholipid antibody induced fetal injury. Blood 2007;110:2423-2431. [PubMed: 17536017]

27. Stegenga ME, van der Crabben SN, Blumer RM, Levi M, Meijers JC, Serlie MJ, Tanck MW, Sauerwein HP, Van Der PT. Hyperglycemia enhances coagulation and reduces neutrophil degranulation, whereas hyperinsulinemia inhibits fibrinolysis during human endotoxemia. Blood 2008;112:82-89. [PubMed: 18316629] 
28. Stephenne X, Vosters O, Najimi M, Beuneu C, Dung KN, Wijns W, Goldman M, Sokal EM. Tissue factor-dependent procoagulant activity of isolated human hepatocytes: relevance to liver cell transplantation. Liver Transpl 2007;13:599-606. [PubMed: 17394166]

29. Su X, Camerer E, Hamilton JR, Coughlin SR, Matthay MA. Protease-activated receptor-2 activation induces acute lung inflammation by neuropeptide-dependent mechanisms. J.Immunol 2005;175:2598-2605. [PubMed: 16081834]

30. van Leeuwen, Gijbels MJ, Duijvestijn A, Smook M, van de Gaar MJ, Heeringa P, de Winther MP, Tervaert JW. Accumulation of myeloperoxidase-positive neutrophils in atherosclerotic lesions in LDLR-/- mice. Arterioscler Thromb Vasc Biol 2008;28:84-89. [PubMed: 17991873]

31. Versteeg HH, Ruf W. Emerging insights in tissue factor-dependent signaling events. Semin.Thromb Hemost 2006;32:24-32. [PubMed: 16479459]

32. Versteeg HH, Ruf W. Tissue factor coagulant function is enhanced by protein-disulfide isomerase independent of oxidoreductase activity. J.Biol Chem 2007;282:25416-25424. [PubMed: 17613528]

33. Weiler-Guettler H, Christie PD, Beeler DL, Healy AM, Hancock WW, Rayburn H, Edelberg JM, Rosenberg RD. A targeted point mutation in thrombomodulin generates viable mice with a prethrombotic state. Journal of Clinical Investigation 1998;101:1983-1991. [PubMed: 9576763]

34. Williams CD, Bajt ML, Farhood A, Jaeschke H. Acetaminophen-induced hepatic neutrophil accumulation and inflammatory liver injury in CD18-deficient mice. Liver Int 2010;30:12801292. [PubMed: 20500806]

35. Xu J, Lee G, Wang H, Vierling JM, Maher JJ. Limited role for CXC chemokines in the pathogenesis of alpha-naphthylisothiocyanate-induced liver injury. Am.J.Physiol Gastrointest.Liver Physiol 2004;287:G734-G741. [PubMed: 15130876] 


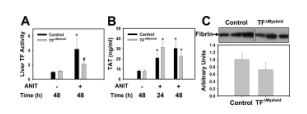

Figure 1. Effect of myeloid cell specific TF deficiency on liver TF activity and coagulation cascade activation in ANIT-treated mice $\mathrm{TF}^{\text {flox/flox}} / \mathrm{Ly}$ sMCre mice $\left(\mathrm{TF}^{\Delta \text { Myeloid }}\right.$ mice) and $\mathrm{TF}^{\text {flox/flox }}$ mice (control mice) were treated with vehicle or ANIT (60 mg/kg, po). (A) Liver TF activity was determined 48 hours later as described (see Methods). $n=5-9$ mice per group. (B) Plasma thrombin-antithrombin levels were determined 24 and 48 hours later. $n=5-12$ mice per group. TAT levels in vehicletreated mice did not differ between 24 and $48 \mathrm{~h}$. Data from $48 \mathrm{~h}$ are shown. (C)

Representative western blot showing hepatic fibrin in liver determined as described in Methods. Quantification ( $n=5-6$ mice per group) by densitometry is shown below. Data are expressed as mean \pm SEM. *Significantly different from vehicle-treated control mice of the same genotype. "Significantly different from ANIT-treated control mice at that time. 


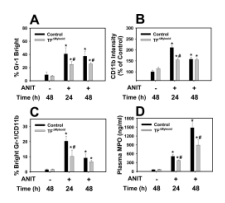

Figure 2. Effect of myeloid cell specific TF deficiency on neutrophil CD11b expression and plasma MPO protein levels in ANIT-treated mice

$\mathrm{TF}^{\text {flox/flox} / L y s M C r e ~ m i c e ~}\left(\mathrm{TF}^{\Delta \text { Myeloid }}\right.$ mice) and $\mathrm{TF}^{\text {flox/flox }}$ mice (control mice) were treated with vehicle or ANIT (60 mg/kg, po). For A-C, flow cytometric analysis was performed as described in Methods to determine the (A) \% Gr-1-high cells (Gr-1 bright), (B) CD11b staining intensity of Gr-1-positive cells, and (C) \% Gr-1-high/CD11b-high (\% Gr-1 bright/ CD11b bright) cells in blood. (D) Plasma MPO protein levels were determined by ELISA. $\mathrm{n}=4-7$ mice per group. Levels of each biomarker in vehicle-treated mice did not differ between 24 and $48 \mathrm{~h}$. Data from $48 \mathrm{~h}$ are shown. Data are expressed as mean \pm SEM. *Significantly different from vehicle-treated control mice of the same genotype. "Significantly different from ANIT-treated control mice at that time. 


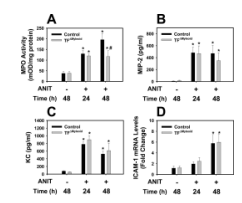

Figure 3. Effect of myeloid cell specific TF deficiency on liver myeloperoxidase activity, and chemokine and ICAM-1 expression in ANIT-treated mice $\mathrm{TF}^{\text {flox/flox}} / \mathrm{LysMCre}$ mice $\left(\mathrm{TF}^{\Delta \text { Myeloid }}\right.$ mice) and $\mathrm{TF}^{\text {flox/flox }}$ mice (control mice) were treated with vehicle or ANIT (60 mg/kg, po) and liver and plasma collected 24 or 48 hours later. (A) Liver homogenate MPO activity was determined as an indicator of neutrophil accumulation. Plasma (B) MIP-2 and (C) KC protein levels were determined by ELISA and (D) hepatic ICAM-1 mRNA levels determined using real-time PCR. $\mathrm{n}=5-12$ mice per group. Levels of each biomarker in vehicle-treated mice did not differ between 24 and $48 \mathrm{~h}$. Data from $48 \mathrm{~h}$ are shown. Data are expressed as mean \pm SEM. *Significantly different from vehicle-treated control mice of the same genotype. "Significantly different from ANITtreated control mice at that time. 

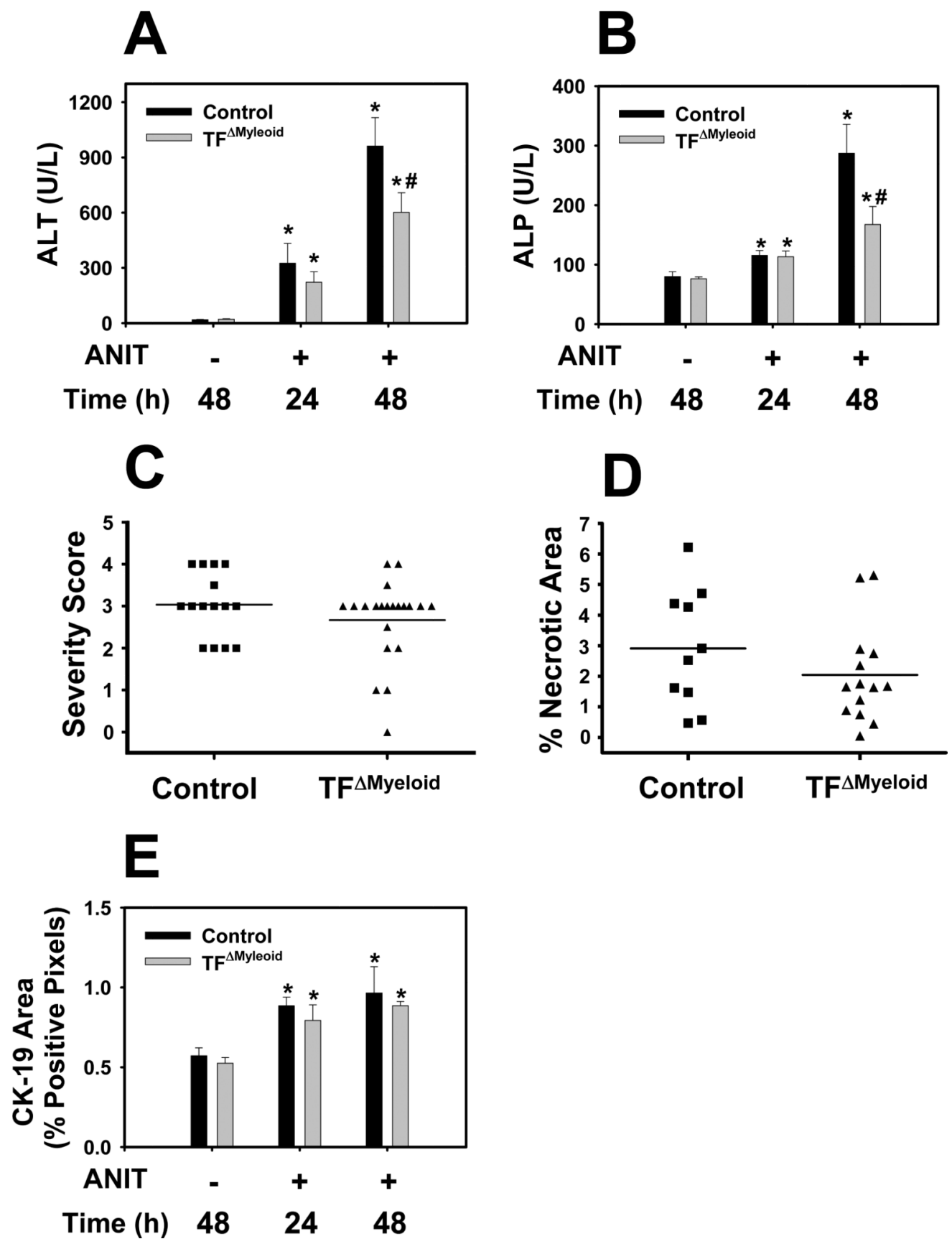

Figure 4. Effect of myeloid cell specific TF deficiency on ANIT-induced liver injury $\mathrm{TF}^{\text {flox/flox} / L y s M C r e ~ m i c e ~(~} \mathrm{TF}^{\Delta M y e l o i d}$ mice) and $\mathrm{TF}^{\text {flox/flox }}$ mice (control mice) were treated with vehicle or ANIT (60 mg/kg, po) and liver and plasma collected 24 or 48 hours later. Serum (A) ALT activity and (B) ALP activity were determined at 24 and 48 hours. The severity of liver necrosis was (C) assigned a severity score by a pathologist and (D) morphometric determination of the percentage of necrotic liver tissue was performed as described in Methods. (E) The area of liver occupied by the biliary marker cytokeratin-19 (CK-19) was determined as described in Methods. Data are expressed as mean \pm SEM. $\mathrm{n}=10-14$ mice per group for A-D and 3 mice per group for $\mathrm{E}$. *Significantly different from vehicle-treated control mice of the same genotype. "Significantly different from ANITtreated control mice at that time. 